\title{
Evaluation of Damage Indices for Rectangular Concrete-filled Steel Tube Structures
}

\author{
Minsheng Guan ${ }^{1}$, Siying Lin ${ }^{1}$, Hongbiao $\mathrm{Du}^{1 *}$, Jie Cui ${ }^{2}$, TaizhouYan ${ }^{1}$ \\ ${ }^{1}$ College of Civil Engineering, Shenzhen University, Shenzhen 518060, P. R. China \\ ${ }^{2}$ Earthquake Engineering Research and Test Center, Guangzhou University, Guangzhou 510405, P. R. China \\ *Corresponding author. E-mail address: gmms361@163.com.
}

\begin{abstract}
The paper aims to select a simple and effective damage index for estimating the extent of damage of rectangular concrete-filled steel tube (RCFT) structures subjected to ground motions. Two experimental databases of cyclic tests conducted on RCFT columns and frames are compiled. Test results from the database are then used to evaluate six different damage indices, including the ductility ratio $(\mu)$, drift ratio, initial-to-secant stiffness ratio $\left(D_{K J}\right)$, modified initial-to-secant stiffness ratio $\left(D_{m s}\right)$, energy coefficient $(E)$, and the combined damage index $\left(D_{P A}\right)$ as a benchmark indicator. Selection criteria including correlation, efficiency, and proficiency are utilized in the selection process. The optimal alternative for $D_{P A}$ is identified on the basis of a comprehensive evaluation. The evaluations indicate that $D_{m s}$ previously proposed by some of the authors is the most appropriate substitution of $D_{P A}$, followed by the drift ratio. For the case of the slenderness ratio less than or equal to 30, the same grades of relation between the investigated damage indices and the benchmark are observed. However, in the case of the slenderness ratio larger than 30 , the drift ratio tends to be the optimal alternative. In most cases, $\mu$ is proved to be an inadequate replacement of $D_{P A}$.
\end{abstract}

Keywords: Rectangular concrete-filled steel tube, damage index, cyclic loading, experimental database, slenderness ratio, evaluation.

\section{INTRODUCTION}

Rectangular concrete-filled steel tubular (RCFT) columns make the best use of the effective material properties of both steel and concrete when compared with steel or reinforced concrete columns alone. Previous research [1]-[3] has shown that RCFT members have higher strength, stiffness, and capacity of energy dissipation in comparison with steel or reinforced concrete structures. Due to their excellent structural performance, RCFT members have been extensively used in various types of structures, particularly in high-rise and super high-rise buildings where higher lateral loads would be experienced. The increasing tendency in using RCFT members requires the estimation of their seismic performance with adequate accuracy.

Performance-based design methodology is commonly used in the seismic design of RCFT structures. This method allows designing earthquake-resistant structures with better reliability [4]. In order to implement this method in the seismic design of RCFT structures, it is essential to have a damage index capable of evaluating the extent of damage of RCFT structures reasonably.

In the past years, numerous efforts have been made to develop damage functions to measure and quantify numerically the damage potential to structures subjected to earthquake excitations [5], [6]. In most cases, the proposed damage indices correlated with maximum deformation experienced by structures or with structural accumulated damage sustained under cyclic loading, whereas, limited studies are found to focus on developing damage parameters in which the combined effects of both excessive deformation and cumulative damage are taken into account. Ideally, a damage index is a dimensionless parameter with a defined scale ranging between 0 (no damage) and 1 (collapse), as well as with intermediate values for corresponding damage states of a structure [5].Generally, these damage indicators can be broadly classified into four categories in accordance with what the indicator allows for: a) displacement; b) stiffness; c) energy; and d) combination of maximum displacement and dissipated energy.

Two deformation-related damage indicators, such as the drift ratio and the ductility ratio, are commonly adopted in the estimation of structural seismic performance for their simplicity and ease of interpretation [5]. However, they were proved to be unreliable indices since the effects of cyclic loading on the structural seismic behaviors are not taken into account [7]. Regardless of those limitations, the two indices are still considered as the crucial design parameters in most current seismic codes. 
Stiffness of a structure after being subjected to earthquakes can often be deteriorated [8]. In order to overcome some of the drawbacks of deformation-based indices, damage parameters associated with stiffness reduction were proposed. The concept of changing in stiffness was firstly adopted by Banon et al. [9] to develop a damage function defined as the flexural damage ratio. And later, this damage function was modified by researchers such as Roufaiel and Meyer [10], and Kunnath and Jenne [11]. Based on the comparison of stiffness of a building before and after an earthquake, Ghobarah et al. [6] proposed a new rational damage indicator by means of two pushover analysis. Another recent stiffness related damage parameter was suggested by Guan et al. [12], in which initial stiffness, the secant stiffness at the performance point for a designed earthquake intensity, and stiffness at failure were considered. Obviously, compared with the deformation-based parameters, there is an improvement due to the consideration of the stiffness deterioration of structures under cyclic loading.

The essence of seismic damage of structures is the procedure of earthquake input energy transfer, conversion, and dissipation [13]. In this respect, energy-based parameters appear to be preferable damage indicators, particularly for ideal ductile systems, in which the failure is principally caused by repeated inelastic deformations [6], [14]. As presented in the literature [15], several measures such as hysteretic energy absorption, and hysteretic energy demand over structural energy dissipation capacity ratio were taken as damage indices. However, these damage indices were not widely used in practical projects since the calculation of values of the earthquake input energy, structural hysteretic energy, and damping energy are rather complicated. On the other hand, the damage caused by the sole excessive deformation, especially for non-ductile buildings, may not be precisely estimated using energy-based parameters.

Clearly, an indicator with the capability to estimate all types of damage of structures sustained under seismic loading should take into account both excessive deformation and cyclic loading effects. By using the linear combination of the two aspects, Park and Ang [16] suggested a combined damage measure and validated it against a large amount of tests of reinforced concrete beam and column components. This combined model is considered to have a significant advantage over the aforementioned damage measures and is widely used in the seismic evaluation of structures. Nevertheless, complication still exists in the calculation of the combined damage index.

It is obvious that most of the damage models discussed were developed and calibrated for reinforced concrete structures. Few studies concerning RCFT structures are found in the literature. Furthermore, a relatively simple damage index used in estimating the degree of damage of RCFT buildings with appropriate accuracy is most needed.

In the current study, the objective is to choose a damage measure with relative simplicity and precision for RCFT buildings. For this purpose, the experimental database composed of 111 RCFT columns under cyclic loading, as well as the database with 22 cyclically loaded RCFT frames, was developed. Four types of damage parameters, including deformation related, stiffness related, energy related and the widely used Park-Ang damage index were selected to represent the current damage indicators proposed in the literature. According to the discussion above, the Park-Ang damage model is utilized as a benchmark measure. The metrics with respect to correlation, efficiency, and proficiency are employed to compare the examined five damage indicators with the benchmark measure. Finally, a comprehensive evaluation approach is utilized to identify the most appropriate alternative index for the Park-Ang index.

\section{DAMAGE INDICES}

In the present work, six damage indices related to deformation, stiffness, energy, and combination of deformation and accumulative effect are chosen as the investigated indicators. The main features of each type of damage index are briefly discussed.

\subsection{Deformation-based indices}

Two widely used damage indices regarding deformation capacity are ductility and drift ratios due to their simplicity and easy interpretation [5]. The ductility can be calculated by the maximum deformation of members or structures over that of yield value ratio, in which the deformation is broadly expressed as rotation, curvature or displacement. For instance, the ductility ratio related to the displacement of a structure is defined as

$$
\mu=\frac{u_{m}}{u_{y}}
$$

where, $\mu$ denotes the ductility ratio; $u_{m}$ represents the maximum displacement, and $u_{y}$ is the yield displacement obtained by the R-park method [17].

The same as ductility ratio, drift ratio is commonly utilized as a crucial performance index in the seismic design of buildings as well. However, the effect of cumulative damage on structures caused by the duration of ground motions cannot be considered [5], [7].

\subsection{Stiffness-based indices}

Degradations in stiffness and strength were observed in members or structures when subjected to cyclic loading. Consequently, attempts to develop damage models with respect to stiffness deterioration have been made by researchers. A stiffness-related measure proposed by Kunnath and Jenne [11] is defined as initial rigidity over secant rigidity at the maximum deformation ratio, as presented below:

$$
D_{K J}=1-\frac{K_{m}}{K_{0}}
$$


where, $K_{0}$ denotes pre-yield stiffness; and $K_{m}$ represents secant rigidity corresponding to the maximum deformation. The indicator $D_{K J}$, however, may underestimate the real damage extent of structures subjected to earthquakes since the structural ultimate state was not considered. Consequently, some authors modified the form of initial stiffness over reduced secant stiffness ratio and suggested a new damage index as given below [12]

$$
D_{m s}=\frac{K_{0}-K_{s}}{K_{0}-K_{u, s}}
$$

where, $K_{0}$ is initial stiffness; $K_{s}$ denotes the secant stiffness at the maximum displacement; and $K_{u, s}$ represents the secant stiffness at the ultimate displacement under a static monotonic load.

\subsection{Energy-based indices}

Generally, the seismic behavior of structures mainly depends on the capacity of energy dissipation. In this regard, a building would survive an earthquake with the energy dissipation capacity above the earthquake input energy. Therefore, the energy dissipation capacity can be utilized as a key indicator to measure damage in structures [13]. As shown in Fig.1., an energy coefficient is employed as a damage index expressed as:

$$
E=\frac{S_{(A B C+C D A)}}{S_{(O B E+O D F)}}
$$

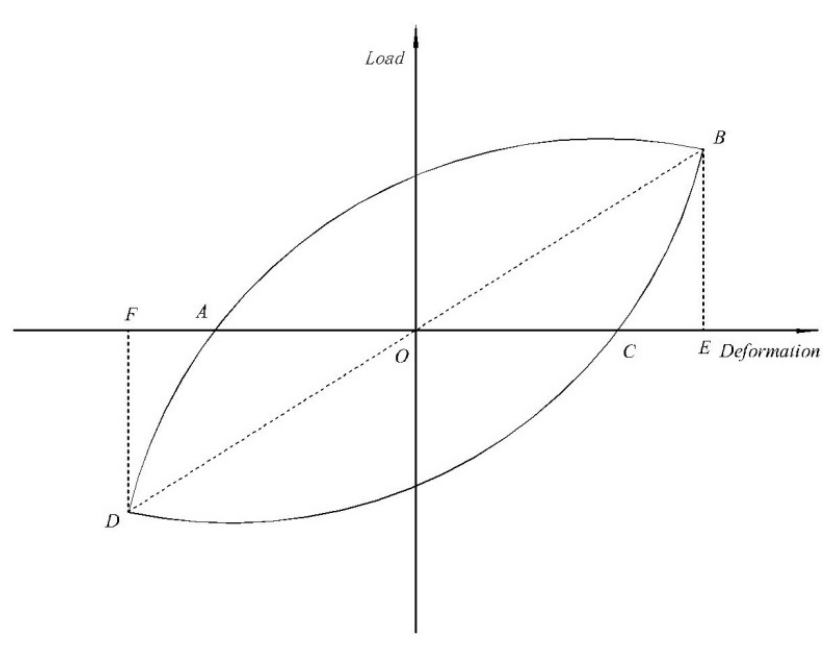

Fig.1. The load-deformation curve.

\subsection{Combined index}

Conventionally, seismic damage of structures would cause the joint actions of both extreme and repeated cycles of deformations [6]. Accordingly, when developing a damage indicator, these two effects should be taken into account.
Such an attempt was made by Park and Ang [16], a combined damage indicator was proposed on the basis of the calibration against observed damage in a large amount of experimental data on reinforced concrete beams and columns. In the paper, this index is utilized as a benchmark and expressed as:

$$
D_{P A}=\frac{u_{m}}{u_{u}}+\beta \frac{E_{h m}}{Q_{y} u_{u}}
$$

where, $u_{m}$ represents the maximum deformation of inelastic response of a component; $u_{u}$ denotes the ultimate deformation of a component subjected to a monotonic load; $E_{h m}$ represents the cumulative hysteretic energy; $Q_{y}$ is the yield strength of component, and $\beta$ is a hysteretic energy factor that considers the contribution of the repeated cycles of deformation to the structural damage and needs calibration from the experiments. Based on the regression analysis of cyclic loading tests on square concrete-filled steel tubular columns, $\beta$ was suggested to be 0.042 [18] and thus was used in the presented study.

\section{DATABASE OF THE EXPERIMENTAL RESEARCH}

\subsection{Database description}

In the present study, two databases documenting experimental results related to RCFT columns and frames were compiled, respectively. In selecting test specimens from published works, only cyclically loaded tests were taken into account. Moreover, specimens with only steel tubes loaded were not included in the database. For each experiment, information, such as material and geometric properties, load and deformation capacities, hysteretic behaviors and evolution of damage, were recorded in detail.

The test set-up for cyclically loaded columns and frames is shown in Fig.2. The specimen was placed in a reaction frame, clamped to lifting jack in the vertical direction and to an actuator in the horizontal direction. During the test, the top of the specimen was loaded vertically. And this vertical load was kept constant. Then, the specimen at the top was cyclically loaded by means of an actuator fixed horizontally to the reaction wall.

In general, the tests were conducted by employing joint controls of load and displacement. Cyclically loading test procedure consists of two stages, that is, pre-yield loading stage, and after yielding stage. In the first phase, the lateral load was controlled by force and one cycle was carried out for each loading level. In the second phase, the cyclic lateral loading with varying amplitudes was controlled by displacement with interval of the estimated lateral yield displacement. Three repeated cycles of displacement were executed on the specimen for each load level until the failed state of the specimen was reached. 


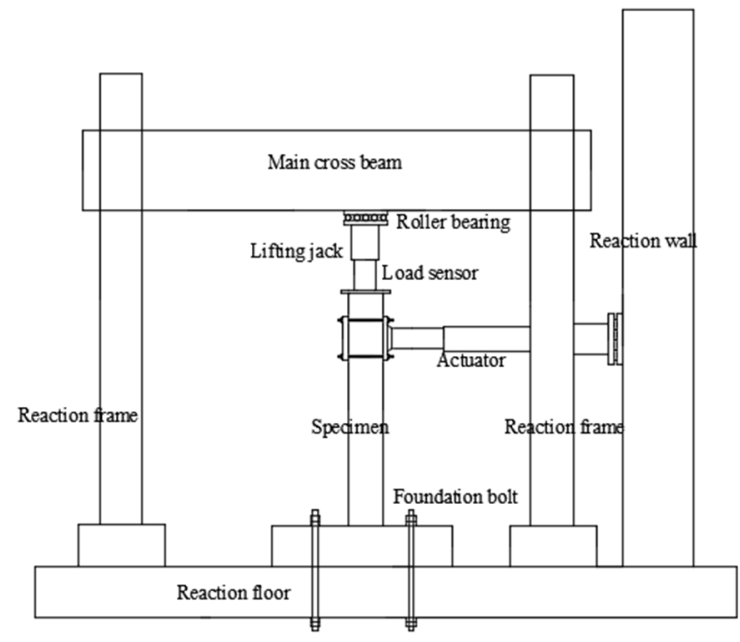

a) Columns

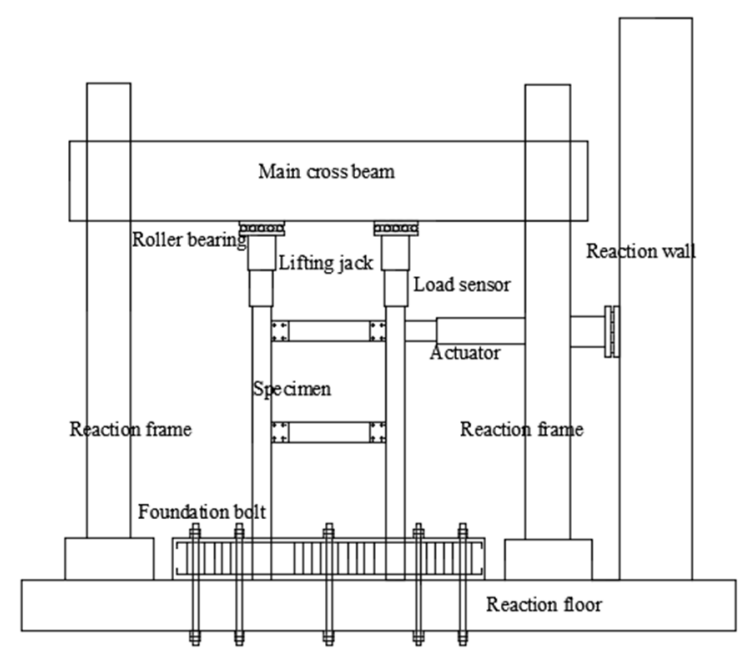

b) Frames

Fig.2. Cyclically loaded test set-up.

\subsection{Database of RCFT column tests}

A total number of 111 cyclically loaded RCFT column specimens were included in the database [19]-[29]. Material parameters including measured compressive strength of concrete $\left(f_{c u}\right)$ and measured yield strength of steel tube $\left(f_{y}\right)$ are described in the database, as shown in Fig.3. The $f_{c u}$ ranged from 16.9 $\mathrm{MPa}$ to $120 \mathrm{MPa}$. As seen from the figure, apart from specimens having super high strength concrete, RCFT column tests with a wide scope of strength grades, including low strength concrete, moderate strength concrete, and high strength concrete, were conducted to examine the seismic performance. For steel tubes, the maximum and minimum values of $f_{y}$ were $242.2 \mathrm{MPa}$ and $660 \mathrm{MPa}$, respectively. The frequency distribution of $f_{y}$ shows that tested RCFT column specimens were higher than those having high yield strength steel tubes.
Geometric facors, such as the ratio of measured depth to width of steel tube $(D / B)$, measured depth over thickness ratio of steel tube $D / t$, and the slenderness ratio $\lambda(\lambda=2 \sqrt{3} L / D)$, are included in the database. Fig.4. demonstrates the histogram of $(D / B)$. It is shown that the cross section types of most specimens are square shaped. As shown in Fig.5., the $(D / t)$ ratios in the cyclically loaded RCFT column database varied between 20 to 81 . What is more, the number of specimens with low to moderate $(D / t)$ ratios are more than those having large values, which indicates that RCFT columns with thin-wall steel tubes need to be further studied. The $\lambda$ ratio of RCFT columns is obtained as the ratio of $2 \sqrt{3}$ measured length ( $L$ ) to depth ( $D$ ) of steel tube, where $D$ is the depth perpendicular to the axis of bending. Fig.6. presents the frequency distribution of $\lambda$ ratios of collected experimental tests, ranging from 7 to 87. As seen from the figure, most researches focused on the RCFT columns with a range of $\lambda$ ratios from 15 to 30 compared with speciemns classified as short $(\lambda \leq 15)$ or slender $(\lambda>30)$ columns.

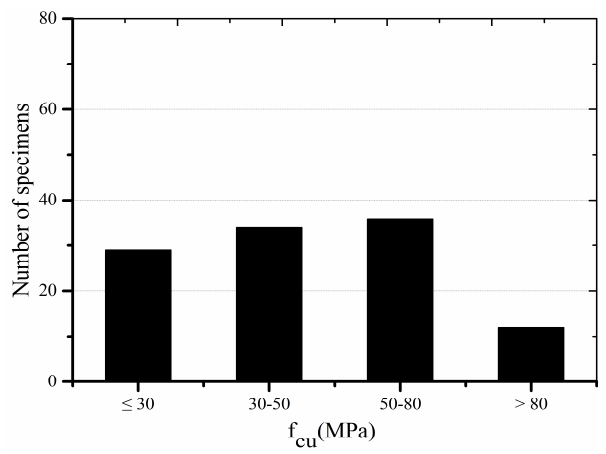

a) Compressive strength of concrete

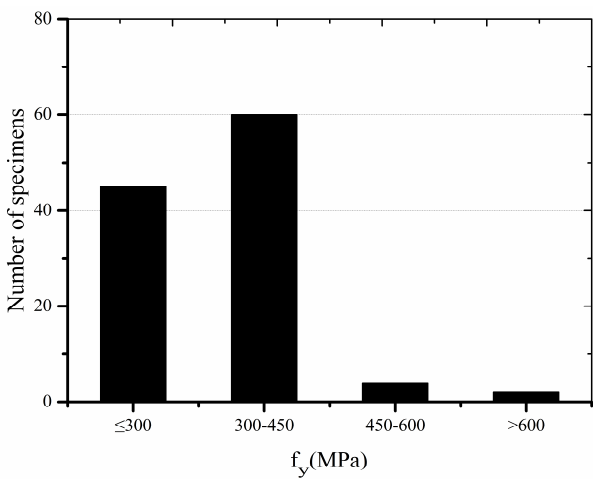

b) Yield strength of steel tube

Fig.3. Measured values of material properties of cyclically loaded RCFT columns 
In addition to the measured material and geometric properties, the axial compression ratio $\left(\mu_{a}\right)$, which is a key factor related to the seismic behaviors of experimental specimens, was also documented in the database, as shown in Fig.7. The maximum $\mu_{a}$ is 0.702 corresponding to a high level of axial compression, while the minimum value 0 indicated no axial load applied on test specimens. It can also be obseved from the figure that RCFT columns with a wide range of $\mu_{a}$ were tested.

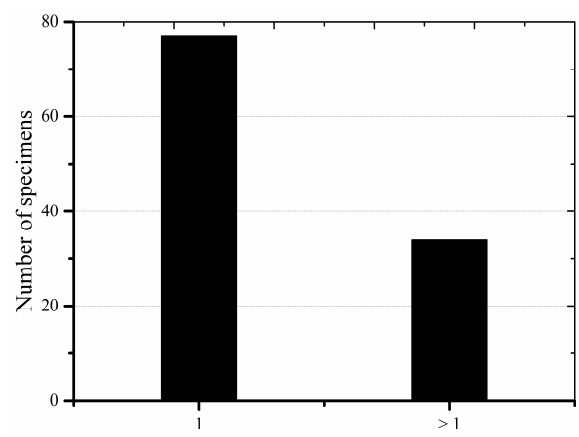

$\mathrm{D} / \mathrm{B}$

Fig.4. $D / B$ ratios of cyclically loaded RCFT columns.

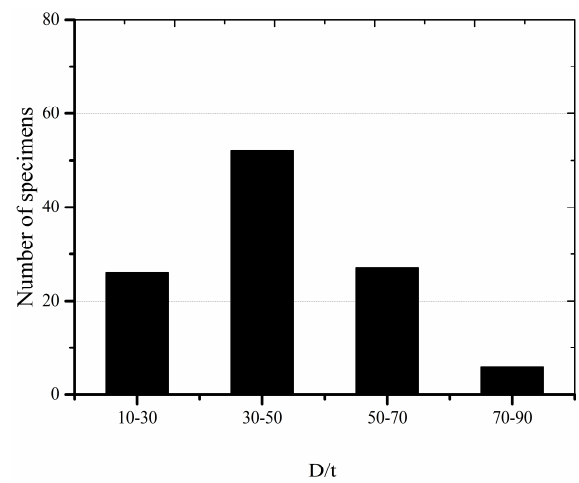

Fig.5. $D / t$ ratios of cyclically loaded RCFT columns.

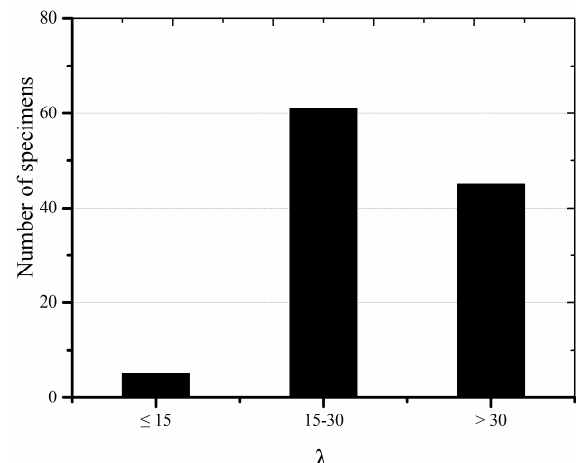

Fig.6. $\lambda$ ratios of cyclically loaded RCFT columns.

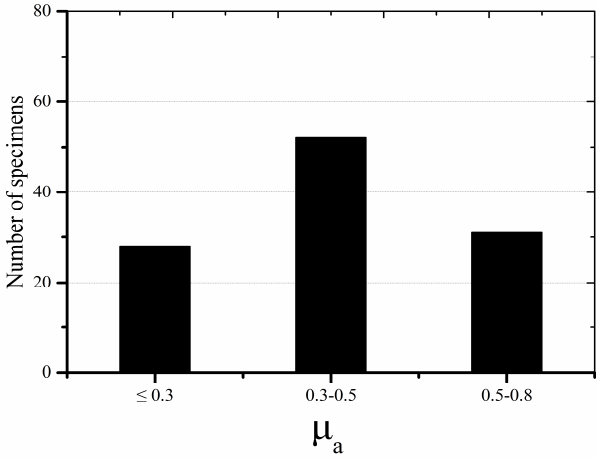

Fig.7. $\mu_{a}$ of cyclically loaded RCFT columns.

\subsection{Database of RCFT frame tests}

Similarily, 22 cyclically loaded RCFT frames were selected from the literature [30]-[38]. According to the compiled data, tested frames with one storey and one span were more comprehensive than specimens with multiple storeyes or spans, as demonstrated in Fig.8. The experimental setup is similar to that of RCFT column tests as mentioned above.

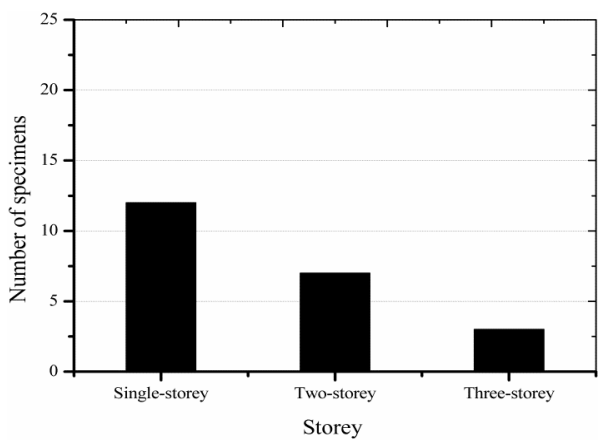

a) Storey

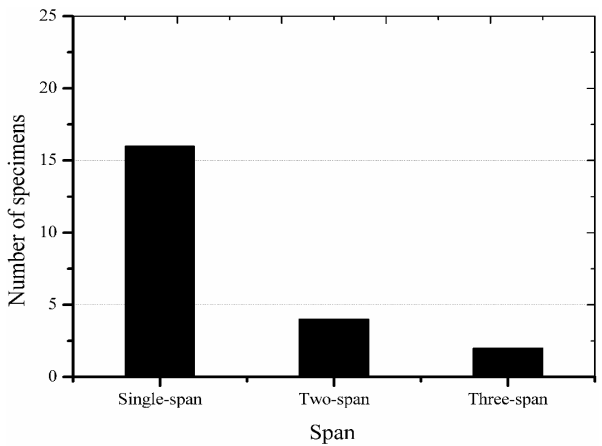

b) Span

Fig.8. Numbers of storey and span of cyclically loaded RCFT frames.

As in the case of the cyclically loaded RCFT column database, same material parameters were recorded in the RCFT frame database. The histogram of $f_{c u}$, ranging between $36.6 \mathrm{MPa}$ and 52.6 MPa, for experimental frames with rectangular steel tubes, is presented in Fig.9.a). 
Obviously, the tests of RCFT frames infilled with low to high strength concrete were mostly conducted, whereas no reports were found in terms of those having super high strength concrete. The maximum and minimum values of $f_{y}$ were $242 \mathrm{MPa}$ and $404 \mathrm{MPa}$, respectively. The frequency distribution of $f_{y}$ in Fig.9.b) indicates that frame specimens with low strength steel tubes are more comprehensively tested compared to those with moderate to high strength steel tubes.

Similar to the RCFT column database, geometric parameters, such as $D / B, D / t$, and $\lambda$, were recorded in the database. The $D / B$ ratios of RCFT frame specimens shown in Fig.10. demonstrate that overwhelming majority of steel tubes are square shaped. The seismic behaviors of frames with $D / B$ ratios larger than 1 should be the focus of further research. The $D / t$ ratios in the compiled database ranged between 24 and 35. As shown in Fig.11., no experiments were conducted on frames made of thinner-wall steel tubes filled with concrete. The histogram of $\lambda$ ratios in the developed database is presented in Fig.12. Obviously, fewer frames of large $\lambda$ ratios $(\lambda>50)$ were investigated compared to those with low and moderate $\lambda$ ratios.

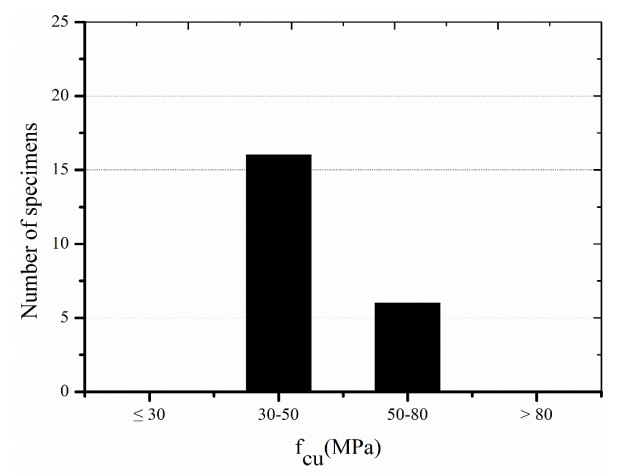

a) Compressive strength of concrete

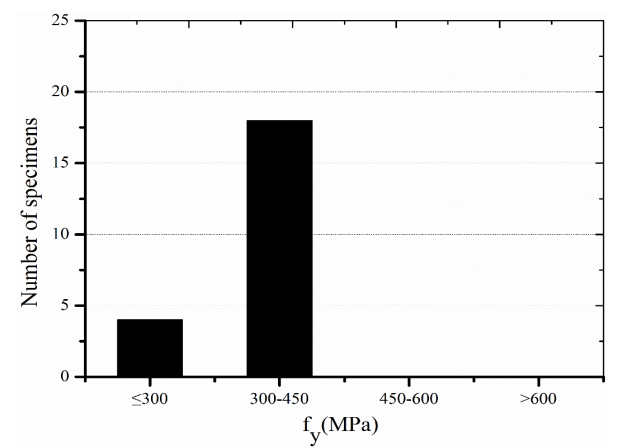

b) Yield strength of steel tube

Fig.9. Measured values of material properties of cyclically loaded RCFT frames.

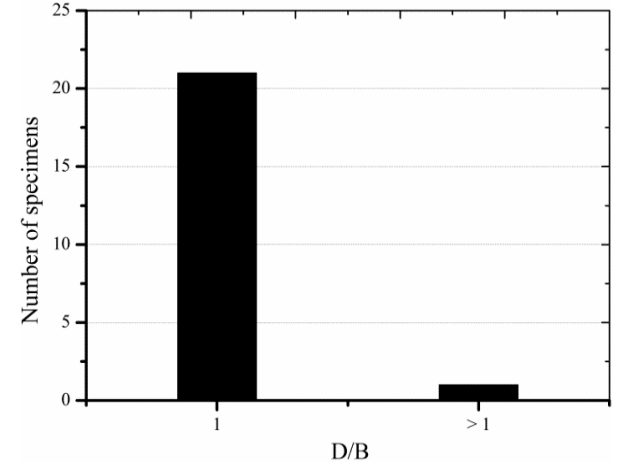

Fig.10. $D / B$ ratios of cyclically loaded RCFT frames.

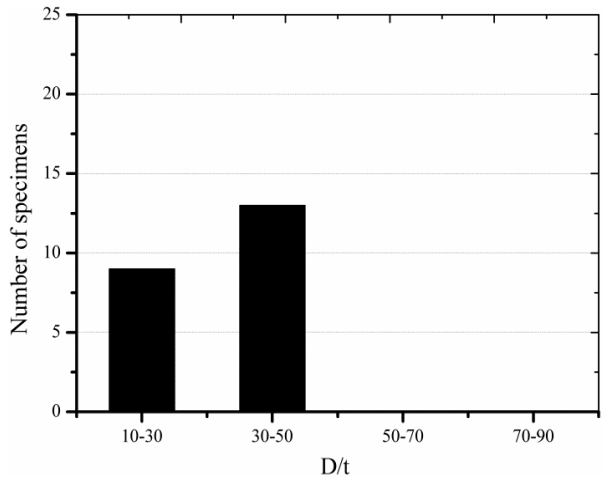

Fig.11. $D / t$ ratios of cyclically loaded RCFT frames.

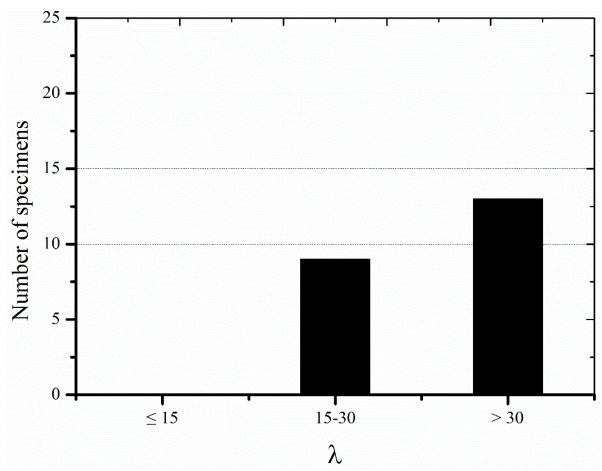

Fig.12. $\lambda$ ratios of cyclically loaded RCFT frames.

\section{NUMERICAL SELECTION PROCEDURES}

As mentioned above, it is very important to precisely assess the state of damage of structures subjected to earthquakes in the performance-based seismic design approach. An appropriate alternative for the Park-Ang index [16] can be obtained by investigating several features between damage indices. The statistic issues studied in the study include correlation, efficiency, and proficiency [39]. In addition, a comprehensive evaluation method was employed in the selection process [40]. This assessment structure can benefit from balancing a number of varying factors and serve to identify an optimal alternative index. 
The grade of interdependency between the examined damage indices and the combination indicator proposed by Park and Ang [16] was evaluated by using a correlation coefficient. For random pairs of data, Pearson's correlation coefficient was generally adopted, as expressed below [41]:

$$
\rho=\frac{\sum_{i=1}^{n}\left(X_{i}-\bar{X}\right)\left(Y_{i}-\bar{Y}\right)}{\sqrt{\sum_{i=1}^{n}\left(X_{i}-\bar{X}\right)^{2}} \sqrt{\sum_{i=1}^{n}\left(Y_{i}-\bar{Y}\right)^{2}}}
$$

where $X$ and $Y$ are the two variables; $\bar{X}$ is the mean value of the variable $X$; and $\bar{Y}$ denotes the mean value of the variable $Y$.

Another parameter, which has been widely utilized for emphasizing the relationship between two variables, is termed efficiency. Smaller value of efficiency implies that the alternative index is more efficient [39]. The relationship between pairs of damage indicators could be estimated by a linear function:

$$
Y=b X+a
$$

where $a$ and $b$ are the regression coefficients.

As a result, the dispersion $\beta$ was given by:

$$
\beta=\sqrt{\frac{\sum_{i=1}^{n}(Y-b X-a)^{2}}{n-2}}
$$

The regression coefficient $b$ is also a good parameter used to measure the degree of correlation between a damage indicator and the Park-Ang index. When the value of the coefficient $b$ approaches to zero, a weak correlation is observed. By modifying the dispersion $\beta$, we suggested a metric for the dependency estimation, which is defined as:

$$
\zeta=\frac{\beta}{b}
$$

An attempt to identify an appropriate alternative on the basis of a unique coefficient would lead to a challenge since different results may exist for the three assessment parameters. Therefore, comprehensive remarks are needed to balance the influences of different factors. In the present study, some assumptions including equal weights of the three methods, higher score for more correlated index and optimal alternative index decided by the highest total score were made when utilizing the comprehensive assessment approach [40].

\section{RESULTS}

\subsection{Statistics of values of performance indices}

According to the test results of the two compiled databases, the values of the six chosen damage indicators for each specimen were calculated. And then, the results of these parameters were statistically analyzed. For simplicity, average value, standard deviation, and coefficient of variation are abbreviated to $\mathrm{AV}, \mathrm{SD}$, and $\mathrm{CV}$, respectively.

Fig.13. presents the statistical results of six damage indices for cyclically loaded columns. As seen from the figure, $D_{m s}$ has the minimum variation coefficient of 0.127 , representing the most stable evaluation of damage states of RCFT members. $D_{K J}$ and $D_{P A}$, as followers, yield less dispersion regarding seismic damage assessment of RCFT columns. Nevertheless, the value of the coefficient of variation of drift ratio shows considerable scatter, indicative of a high degree of instability for the damage assessment.

For the RCFT frames, similar dispersion for the selected damage indices was observed according to the statistical analysis, as shown in Fig.14. It can be seen from the figure that $D_{m s}$ demonstrates the least dispersion about the seismic damage evaluation, followed by $D_{P A}$ and $D_{K J}$. Similarly, the drift ratio exhibits relatively high degree of scatter.

\subsection{Comparison analysis}

\subsubsection{Correlation}

Based on the two compiled databases, i.e. RCFT column database and RCFT frame database, the degradation of correlation between the chosen five indicators and the benchmark measure was investigated by adopting the Pearson coefficient. The absolute values of the Pearson coefficient were calculated using OriginPro 8 software [42], as shown in Table 1. It can be seen that, in general, there is a strong correlation between stiffness related damage indices and the benchmark indicator. On the other hand, in most cases, a weak correlation is observed for ductility ratio $\mu$. In the case of two databases of RCFT columns and frames, $D_{m s}$ exhibits the strongest correlation with the Park-Ang index, followed by the drift ratio, for which a significant correlation with the Park-Ang index was obtained. On the whole, there is, in principle, a low correlation between energy related parameter $E$ and the combined index. 


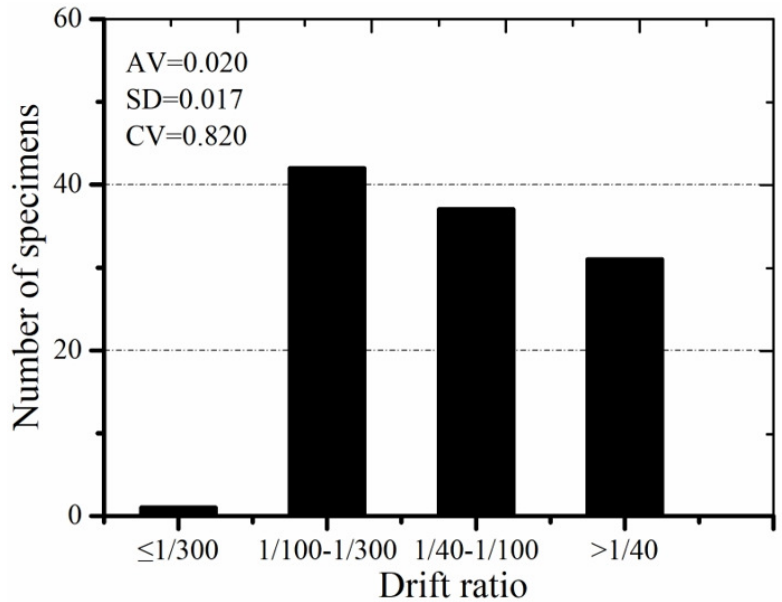

a) Drift ratio

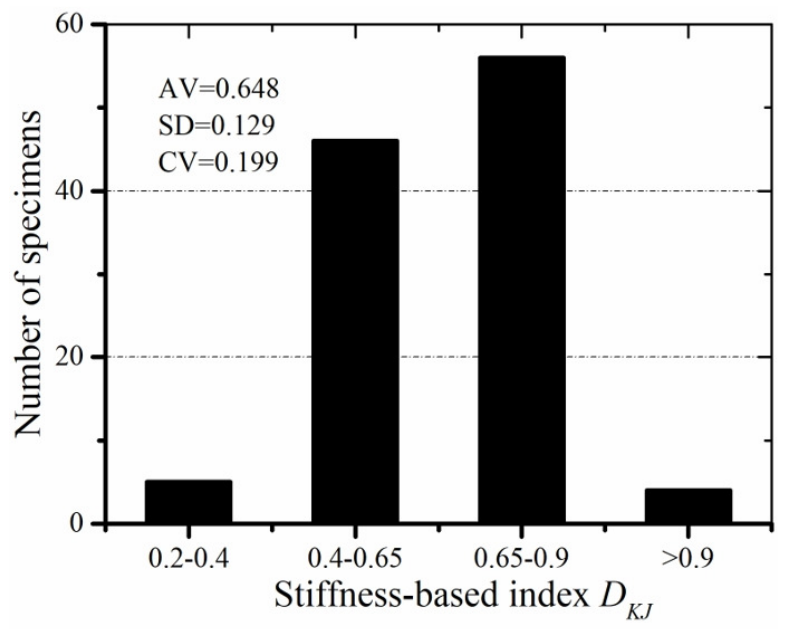

c) Stiffness-based index $D_{K J}$

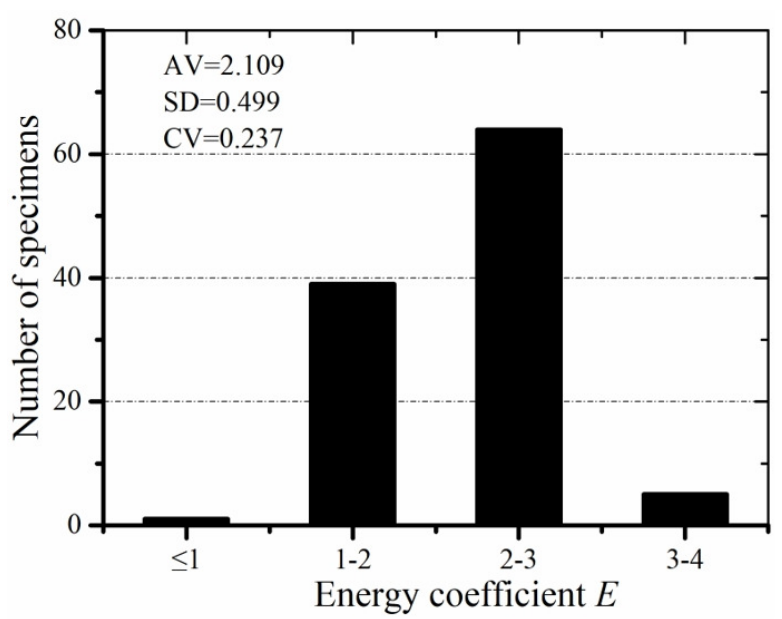

e) Energy coefficient $E$

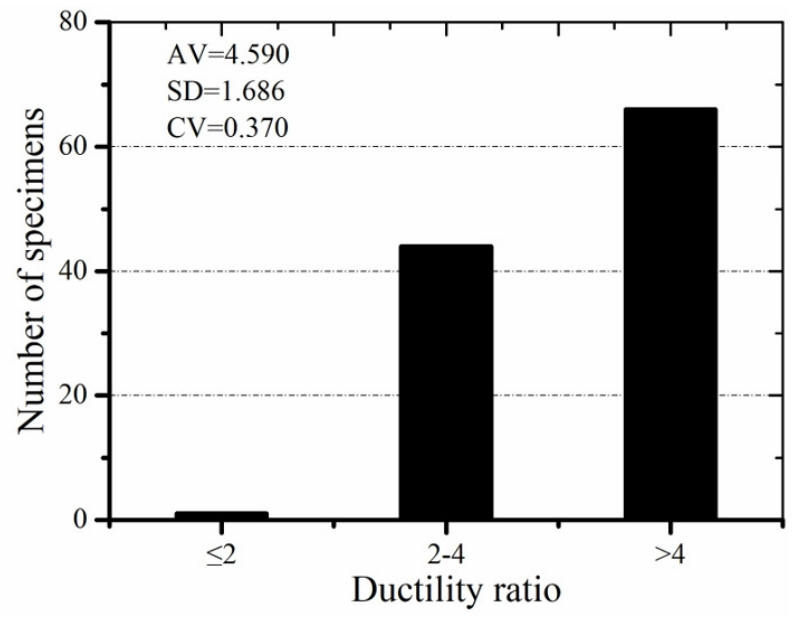

b) Ductility ratio

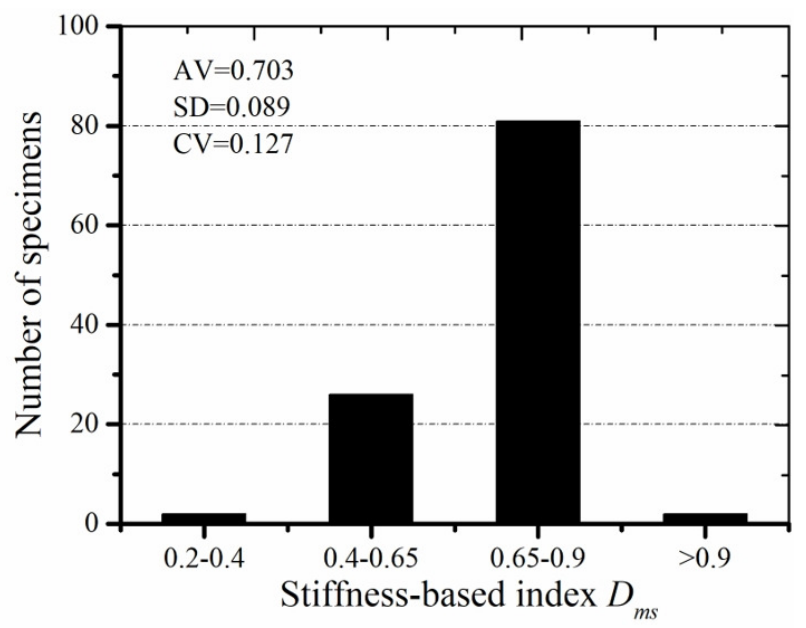

d) Stiffness-based index $D_{m s}$

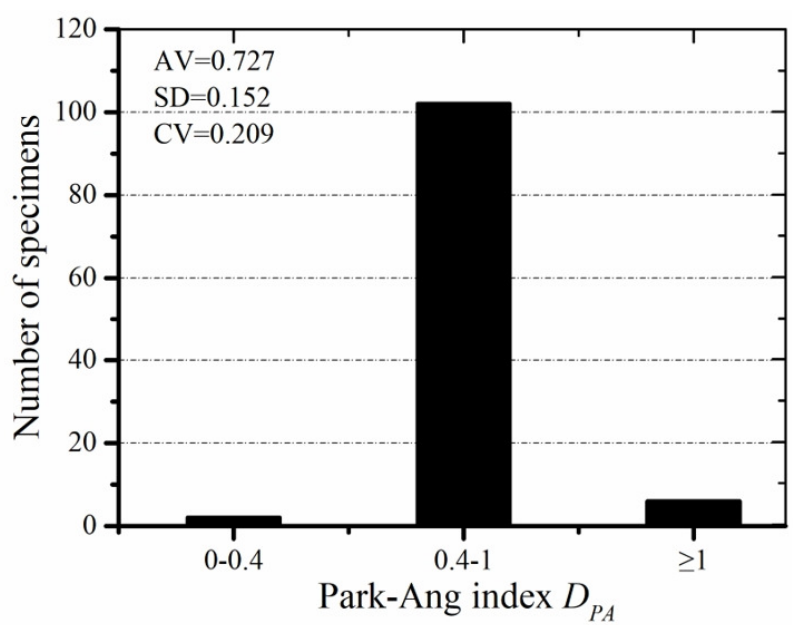

f) Park-Ang index $D_{P A}$

Fig.13. Histogram statistics of varying damage indicators for cyclically loaded RCFT columns. 
MEASUREMENT SCIENCE REVIEW, 19, (2019), No. 4, 170-184

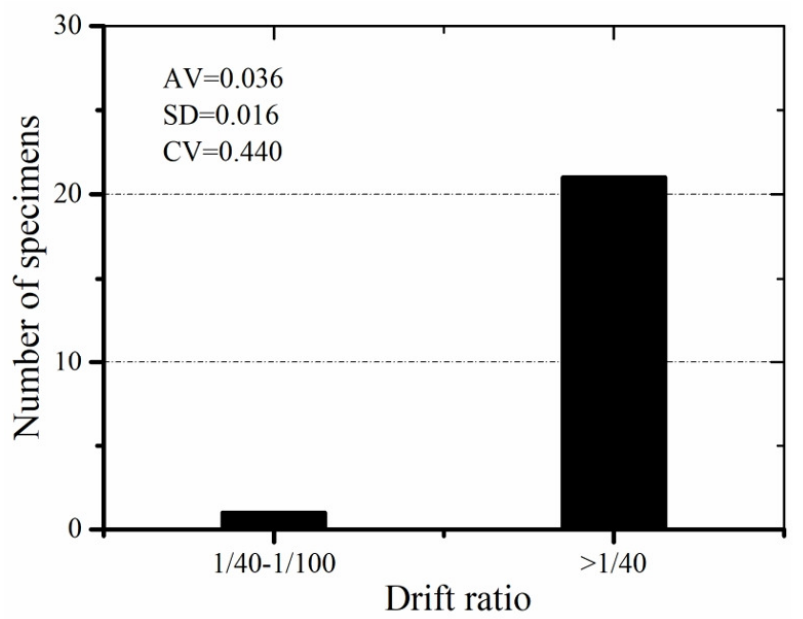

a) Drift ratio

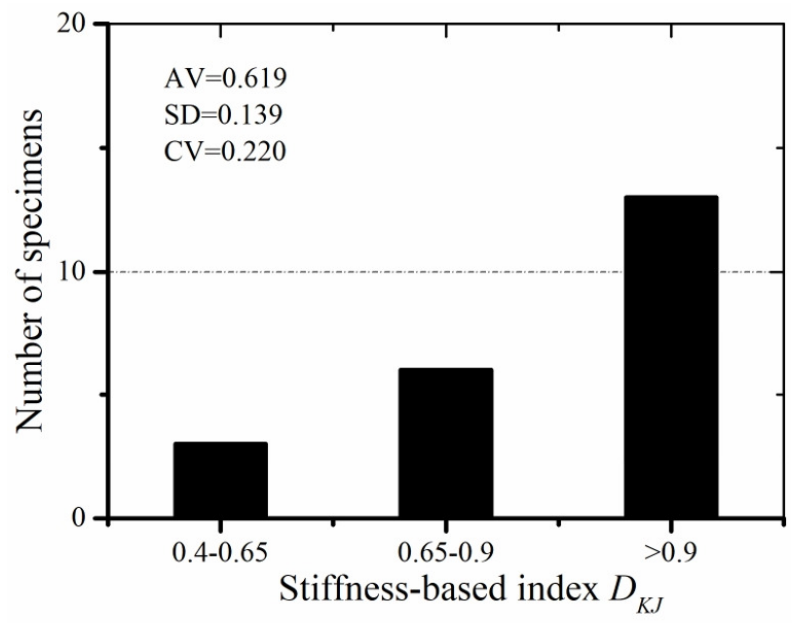

c) Stiffness-based index $D_{K J}$

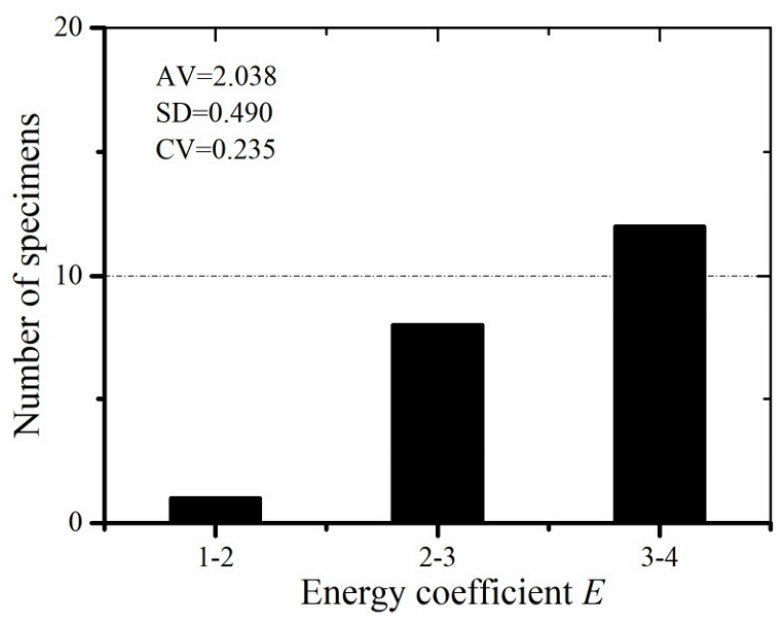

e) Energy coefficient

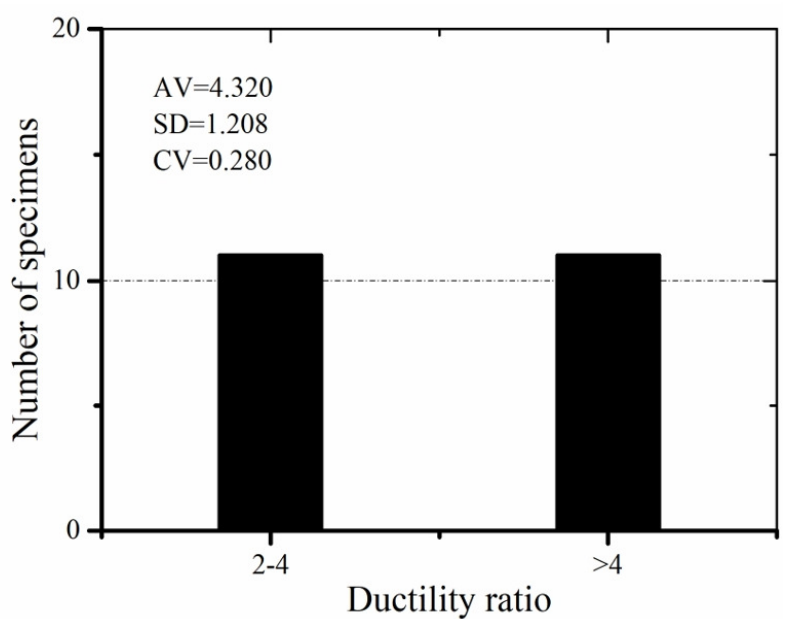

b) Ductility ratio

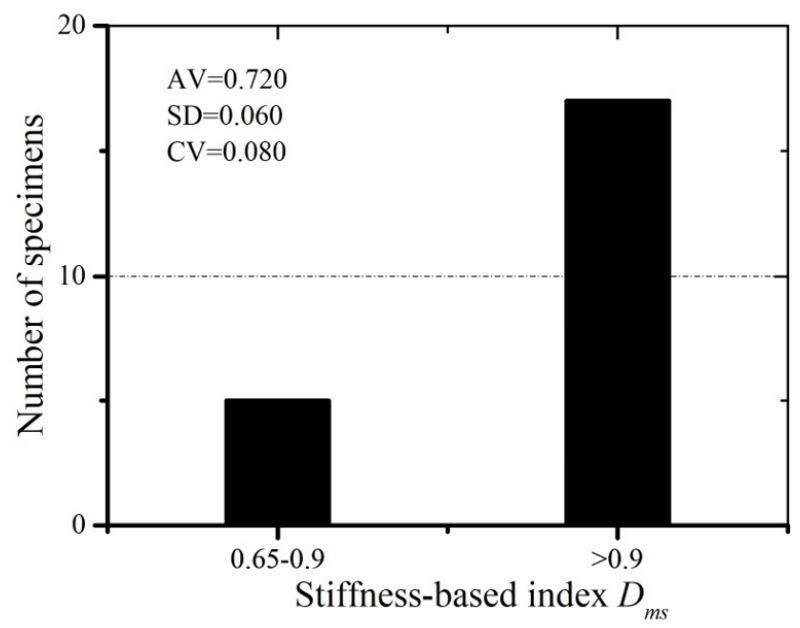

d) Stiffness-based index $D_{m s}$

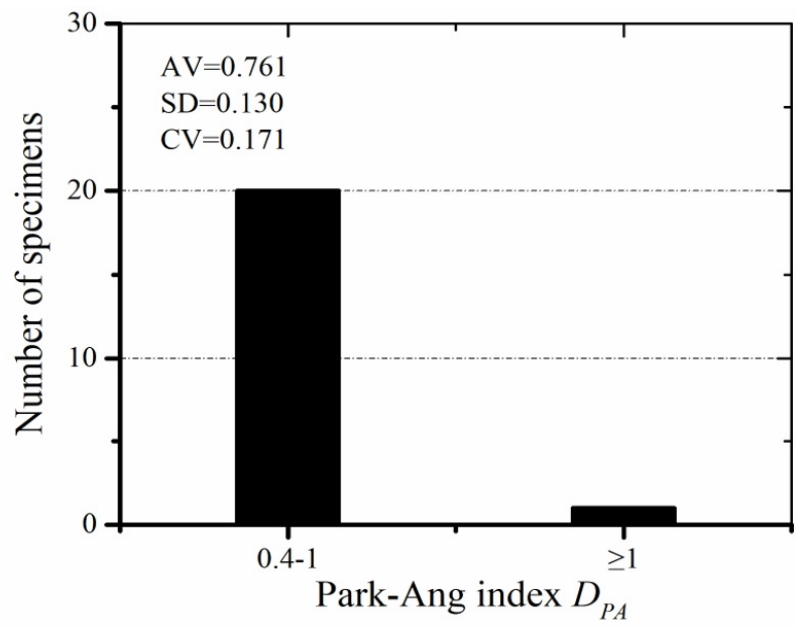

f) Park-Ang index $D_{P A}$

Fig.14. Histogram statistics of varying damage indicators for cyclically loaded RCFT frames. 
Table 1. Correlation coefficients between estimated damage parameters and the Park-Ang index.

\begin{tabular}{ccccc}
\hline & \multicolumn{2}{c}{$\begin{array}{c}\text { RCFT column } \\
\text { database }\end{array}$} & \multicolumn{2}{c}{$\begin{array}{c}\text { RCFT frame } \\
\text { database }\end{array}$} \\
\cline { 2 - 5 } Damage index & Rank & $|\rho|$ & Rank \\
\hline Drift ratio & 0.460 & 3 & 0.601 & 2 \\
$\mu$ & 0.384 & 5 & 0.371 & 4 \\
$D_{K J}$ & 0.403 & 4 & 0.409 & 3 \\
$D_{m s}$ & 0.665 & 1 & 0.627 & 1 \\
$E$ & 0.513 & 2 & 0.320 & 5 \\
\hline
\end{tabular}

\subsubsection{Efficiency}

As indicated above, the relative efficiency of varying indices can be evaluated through the comparison of the corresponding dispersion. The values of efficiency of the five examined damage measures and the Park-Ang index for the two constructed databases are presented in Table 2. On the whole, as seen in Table 2., slight differences in $\beta$-values exist for the inspected indicators. Generally, the relations between the five indices and the benchmark indicator are similar to those of correlation assessment. In all cases, $D_{m s}$ tends to be the most efficient alternative index, followed by drift ratio. On the other hand, several damage indices including $\mu, D_{K J}$, and $E$ tend to have nearly similar degrees of efficiency.

\subsubsection{Proficiency}

Similarly, levels of proficiency of the inspected damage parameters are also obtained by investigating values of proficiency parameter $\zeta$, which are illustrated in Table 3. In contrast to the estimation of correlation and efficiency, drift ratio is the most appropriate alternative index on the basis of the proficiency values presented in Table 3. $D_{m s}$ is downgraded as a follower. In the cases of the two developed databases, two of the five damage indicators, namely, $E$ and $\mu$, appear to be a less appropriate substitution of the combined index.

\subsubsection{Comprehensive assessment}

The optimal alternative damage indicator for the Park-Ang damage index, which can be employed in seismic damage assessment of RCFT structures, was identified on the basis of the evaluation of correlation, efficiency, and proficiency. Each score of $\rho, \beta$, and $\zeta$, as well as the final score of those estimation coefficients, was calculated in Table 4. According to the selection criteria, $D_{m s}$, ranked in the top one, tends to be the most appropriate substitution. The next one is drift ratio. However, it should be pointed out that stiffness related damage index $D_{K J}$ was proved to be not a good alternative. What is more, based on the scores presented in Table 4., $\mu$ appears to be the least appropriate replacement for the combined index.

Table 2. Efficiency coefficients between estimated damage parameters and the Park-Ang index.

\begin{tabular}{ccccc}
\hline & \multicolumn{2}{c}{$\begin{array}{c}\text { RCFT column } \\
\text { database }\end{array}$} & \multicolumn{2}{c}{$\begin{array}{c}\text { RCFT frame } \\
\text { database }\end{array}$} \\
\cline { 2 - 5 } Damage index & $\beta$ & Rank & $\beta$ & Rank \\
\hline Drift ratio & 0.136 & 3 & 0.109 & 2 \\
$\mu$ & 0.141 & 5 & 0.127 & 3 \\
$D_{K J}$ & 0.140 & 4 & 0.147 & 5 \\
$D_{m s}$ & 0.114 & 1 & 0.107 & 1 \\
$E$ & 0.132 & 2 & 0.130 & 4 \\
\hline
\end{tabular}


Table 3. Proficiency coefficients between estimated damage parameters and the Park-Ang index.

\begin{tabular}{ccccc}
\hline & \multicolumn{2}{c}{$\begin{array}{c}\text { RCFT column } \\
\text { database }\end{array}$} & \multicolumn{2}{c}{$\begin{array}{c}\text { RCFT frame } \\
\text { database }\end{array}$} \\
\cline { 2 - 5 } Damage index & $\zeta$ & Rank & $\zeta$ & Rank \\
\hline Drift ratio & 0.032 & 1 & 0.020 & 1 \\
$\mu$ & 4.099 & 5 & 2.965 & 5 \\
$D_{K J}$ & 0.205 & 3 & 0.178 & 3 \\
$D_{m s}$ & 0.147 & 2 & 0.177 & 2 \\
$E$ & 0.847 & 4 & 1.530 & 4 \\
\hline
\end{tabular}

Table 4. The scores of varying estimation coefficients.

\begin{tabular}{ccccccccc}
\hline & \multicolumn{3}{c}{$\begin{array}{c}\text { RCFT column } \\
\text { database }\end{array}$} & \multicolumn{3}{c}{$\begin{array}{c}\text { RCFT frame } \\
\text { database }\end{array}$} & Final & Rank \\
\cline { 2 - 7 } Damage index & $|\rho|$ & $\beta$ & $\zeta$ & $|\rho|$ & $\beta$ & $\zeta$ & & \\
\hline \multicolumn{1}{c}{ Drift ratio } & 3 & 3 & 5 & 4 & 4 & 5 & 24 & 2 \\
$\mu$ & 1 & 1 & 1 & 2 & 3 & 1 & 9 & 5 \\
$D_{K J}$ & 2 & 2 & 3 & 3 & 1 & 3 & 14 & 4 \\
$D_{m s}$ & 5 & 5 & 4 & 5 & 5 & 4 & 28 & 1 \\
$E$ & 4 & 4 & 2 & 1 & 2 & 2 & 15 & 3 \\
\hline
\end{tabular}

\subsection{Influence of $\lambda$ ratios}

The column slenderness ratio $\lambda$ is a crucial parameter by which the mechanical behaviors of RCFT columns and frames are drastically affected [43]-[46]. Columns with higher $\lambda$ ratios subjected to a combined action of constant vertical load and cyclic loading are more prone to be locally or overall buckled. As a result, load and deformation capacity of members, as well as energy dissipation capacity, were severely reduced as $\lambda$ ratios were getting larger. In this regard, experimental specimens recorded in the two databases are categorized into two groups in accordance with the values of slenderness ratio, namely $\lambda \leq 30$, representing low to moderate slenderness and $\lambda>30$, indicative of high slenderness.

As mentioned above, for the two compiled databases with slenderness ratio less than 30 , the coefficients regarding correlation, efficiency, and proficiency were computed for five examined damage indices and the Park-Ang index, as shown in Table 5. Apart from the proficiency estimation, $D_{m s}$ exhibits the strongest correlation and the highest efficiency with the combined damage index. Moreover, it must be noticed that drift ratio shows, in principle, significant correlation, high efficiency and the most proficiency. As indicated in the same table, it is obvious that there are weak correlation, low efficiency, and less proficiency between $\mu$ and the Park-Ang index.

Table 6. presents the comprehensive evaluation in the case of $\lambda>30$ for both sets of data, including scores of three inspected coefficients and the sum of the values. Clearly, the same rank class as in Table 4. was observed, for which the $D_{m s}$ ranks in the top one and thus tends to be the most appropriate alternative. Furthermore, drift ratio is also a close contender, whereas, it can be seen that $\mu$ appears to be an inappropriate substitution of the Park-Ang index. 
MEASUREMENT SCIENCE REVIEW, 19, (2019), No. 4, 170-184

Table 5. The values of varying estimation coefficients for $\lambda \leq 30$.

\begin{tabular}{|c|c|c|c|c|c|c|}
\hline \multirow{2}{*}{$\begin{array}{l}\text { Damage } \\
\text { index }\end{array}$} & \multicolumn{3}{|c|}{ RCFT column database } & \multicolumn{3}{|c|}{ RCFT frame database } \\
\hline & $|\rho|$ & $\beta$ & $\zeta$ & $|\rho|$ & $\beta$ & $\zeta$ \\
\hline $\begin{array}{l}\text { Drift } \\
\text { ratio }\end{array}$ & 0.448 & 0.165 & 0.039 & 0.548 & 0.129 & 0.031 \\
\hline$\mu$ & 0.358 & 0.173 & 5.361 & 0.260 & 0.149 & 4.407 \\
\hline$D_{K J}$ & 0.370 & 0.172 & 0.271 & 0.100 & 0.154 & 0.584 \\
\hline$D_{m s}$ & 0.702 & 0.132 & 0.153 & 0.835 & 0.085 & 0.109 \\
\hline$E$ & 0.530 & 0.157 & 0.875 & 0.347 & 0.145 & 1.348 \\
\hline
\end{tabular}

Table 6. The scores of varying estimation coefficients for $\lambda \leq 30$.

\begin{tabular}{|c|c|c|c|c|c|c|c|c|}
\hline \multirow{2}{*}{ Damage index } & \multicolumn{3}{|c|}{$\begin{array}{c}\text { RCFT column } \\
\text { database }\end{array}$} & \multicolumn{3}{|c|}{$\begin{array}{c}\text { RCFT frame } \\
\text { database }\end{array}$} & \multirow{2}{*}{ Final } & \multirow{2}{*}{ Rank } \\
\hline & $|\rho|$ & $\beta$ & $\zeta$ & $|\rho|$ & $\beta$ & $\zeta$ & & \\
\hline Drift ratio & 3 & 3 & 5 & 4 & 4 & 5 & 24 & 2 \\
\hline$\mu$ & 1 & 1 & 1 & 2 & 2 & 1 & 8 & 5 \\
\hline$D_{K J}$ & 2 & 2 & 3 & 1 & 1 & 3 & 12 & 4 \\
\hline$D_{m s}$ & 5 & 5 & 4 & 5 & 5 & 4 & 28 & 1 \\
\hline$E$ & 4 & 4 & 2 & 3 & 3 & 2 & 18 & 3 \\
\hline
\end{tabular}

Table 7. The values of varying estimation coefficients for $\lambda>30$.

\begin{tabular}{|c|c|c|c|c|c|c|}
\hline \multirow{2}{*}{$\begin{array}{l}\text { Damage } \\
\text { index }\end{array}$} & \multicolumn{3}{|c|}{$\begin{array}{c}\text { RCFT column } \\
\text { database }\end{array}$} & \multicolumn{3}{|c|}{$\begin{array}{c}\text { RCFT frame } \\
\text { database }\end{array}$} \\
\hline & $|\rho|$ & $\beta$ & $\zeta$ & $|\rho|$ & $\beta$ & $\zeta$ \\
\hline Drift ratio & 0.625 & 0.075 & 0.010 & 0.712 & 0.094 & 0.012 \\
\hline$\mu$ & 0.616 & 0.076 & 1.124 & 0.470 & 0.118 & 1.445 \\
\hline$D_{K J}$ & 0.600 & 0.077 & 0.081 & 0.604 & 0.107 & 0.075 \\
\hline$D_{m s}$ & 0.478 & 0.084 & 0.181 & 0.557 & 0.111 & 0.192 \\
\hline$E$ & 0.532 & 0.081 & 0.707 & 0.355 & 0.125 & 1.497 \\
\hline
\end{tabular}


Table 8. The scores of varying estimation coefficients for $\lambda>30$.

\begin{tabular}{ccccccccc}
\hline & \multicolumn{3}{c}{$\begin{array}{c}\text { RCFT column } \\
\text { database }\end{array}$} & \multicolumn{3}{c}{$\begin{array}{c}\text { RCFT frame } \\
\text { database }\end{array}$} & Final & Rank \\
\cline { 2 - 6 } & $|\rho|$ & $\beta$ & $\zeta$ & $|\rho|$ & $\beta$ & $\zeta$ & & \\
\hline Drift ratio & 5 & 5 & 5 & 5 & 5 & 5 & 30 & 1 \\
$\mu$ & 4 & 4 & 1 & 2 & 2 & 2 & 15 & 3 \\
$D_{K J}$ & 3 & 3 & 4 & 4 & 4 & 4 & 22 & 2 \\
$D_{m s}$ & 1 & 1 & 3 & 3 & 3 & 3 & 14 & 4 \\
$E$ & 2 & 2 & 2 & 1 & 1 & 1 & 9 & 5 \\
\hline
\end{tabular}

The results of correlation, efficiency, and proficiency analyses on the basis of the two compiled test data with slenderness ratio above 30 are illustrated in Table 7. According to the assumptions proposed above, the scores and the corresponding ranks are shown in Table 8. as well. It is worth pointing out that, in all cases, drift ratio demonstrates the strongest correlation, the highest efficiency and the most proficiency with the benchmark indicator and thus appears to be the most appropriate alternative damage index. This result can be attributed to the fact that the behaviors of the RCFT columns and frames are governed by the deformation in the case of large slenderness ratio. As seen from Table 7. and Table 8., $D_{K J}$ and $\mu$ can be taken as the next two candidates. However, two measures with respect to $D_{m s}$ and $E$ are found unsuitable to represent the Park-Ang damage index.

\section{CONCLUSIONS}

The present study has attempted to identify an optimal alternative for the Park-Ang index which has been employed to assess the seismic performance of rectangular concretefilled steel tube (RCFT) structures. Two experimental databases associated with 111 RCFT columns and 22 RCFT frames under cyclic loading have been constructed. The multi-metrics including correlation, efficiency, and proficiency have been used to evaluate the relation between the chosen damage indicators and the Park-Ang measure. Eventually, a comprehensive evaluation approach has been used to find the most appropriate alternative index for the Park-Ang index. Comments and findings are drawn as follows:

1) The modified initial-to-secant stiffness ratio $D_{m s}$ previously proposed by some of the authors provides a stable estimation of the seismic behaviors of RCFT structures.

2) $D_{m s}$ is found to be the most appropriate substitution of the Park-Ang damage index. As a whole, $D_{m s}$ shows the strongest correlation, the highest efficiency and best proficiency with the Park-Ang index.
3) In most cases, particularly with RCFT frame database, the drift ratio has a slight disadvantage over $D_{m s}$, indicative of a follow alternative.

4) In the case of the slenderness ratio $\lambda$ greater than 30 , the drift ratio is proved to be the optimal alternative for the combined damage index, which indicated that seismic behaviors of RCFT structures with high slenderness ratios are controlled by deformation or displacement.

5) The ductility ratio $\mu$ is considered to be an inappropriate alternative while, in the case of $\lambda>30, \mu$ appears to be a moderately appropriate substitution.

It should be noted that the findings have been drawn from the analysis of the two developed experimental databases, namely, the RCFT column database and the RCFT frame database. However, since limited test results of RCFT columns and frames are available, larger specimen data set, especially for the RCFT frame tests, is needed to yield greater statistical validity and to enhance the quantitative aspect in the future studies.

\section{ACKNOWLEDGEMENTS}

This project is sponsored by the Intellectual Innovation Program of Shenzhen Science and Technology Innovation Committee (JCYJ20160331114415945 and JCYJ20170818142117164), and by the Natural Science Foundation of Shenzhen University (2017062).

\section{REFERENCES}

[1] Kwon, Y.B., Jeong, I.K. (2014). Resistance of rectangular concrete-filled tubular (CFT) sections to the axial load and combined axial compression and bending. Thin-Walled Structures, 79, 178-186.

[2] Goto, Y., Mizuno, K., Prosenjit, K.G. (2012). Nonlinear finite element analysis for cyclic behavior of thinwalled stiffened rectangular steel columns with in-filled concrete. Journal of Structural Engineering, 138 (5), 571-584. 
[3] Lai, Z., Varma, A.H., Zhang, K. (2014). Noncompact and slender rectangular CFT members: Experimental database, analysis, and design. Journal of Constructional Steel Research, 101, 455-468.

[4] Ellingwood, B.R. (2008). Structural reliability and performance-based engineering. Proceedings of the Institution of Civil Engineers-Structures and Buildings, 161 (4), 199-207.

[5] Williams, M.S., Sexsmith, R.G. (1995). Seismic damage indices for concrete structures: A state-of-theart review. Earthquake Spectra, 11 (2), 319-349.

[6] Ghobarah, A., Abou, E.H., Biddah, A. (1999). Response-based damage assessment of structures. Earthquake Engineering \& Structural Dynamics, 28 (1), 79-104.

[7] Khashaee, P. (2005). Damage-based seismic design of structures. Earthquake Spectra, 21 (2), 371-387.

[8] Kaptan, K. (2017). Effectiveness of externally bonded FRP systems in strengthening of RC structures in seismic areas. Proceedings of the Institution of Civil Engineers-Structures and Buildings, 170 (5), 362-375.

[9] Banon, H., Irvine, H.M., Biggs, J.M. (1981). Seismic damage in reinforced concrete frames. Journal of the Structural Division, 107 (9), 1713-1729.

[10] Roufaiel, M.S.L., Meyer, C. (1987). Analytical modeling of hysteretic behavior of $\mathrm{R} / \mathrm{C}$ frames. Journal of Structural Engineering-ASCE, 113 (3), 429-444.

[11] Kunnath, S., Jenne, C. (1994). Seismic damageassessment of inelastic RC structures. In 5 th US National Conference on Earthquake Engineering. Chicago, Illinois: EERI, 55-64.

[12] Guan, M., Han, D., Du, H., Wu, Y. (2011). A new seismic performance index for reinforced concrete frame structures (press in Chinese). Journal of Shenzhen University Science and Engineering, 28 (3), 200-205.

[13] Guan, M., Du, H. (2013). Energy-based seismic performance of reinforced concrete frame structures. Magazine of Concrete Research, 65 (8), 494-505.

[14] Guan, M., Du, H., Cui, J., Feng, W., Jiang, H. (2017). Correlation of a new index with energy-based damage indices. Proceedings of the Institution of Civil Engineers-Structures and Buildings, 170 (1), 51-66.

[15] Rodriguez, M.E., Padilla, D. (2009). A damage index for the seismic analysis of reinforced concrete members. Journal of Earthquake Engineering, 13 (3), 364-383.

[16] Park, Y.J., Ang, A.H.S. (1985). Mechanistic seismic damage model for reinforced concrete. Journal of Structural Engineering-ASCE, 111 (4), 722-739.

[17] Guan, M., Liu, W., Lai, M., Du, H., Cui, J., Gan, Y. (2019). Seismic behaviour of innovative composite walls with high-strength manufactured sand concrete. Engineering Structures, 195, 182-199.

[18] Guo, R., Wang, T., Zhao, S., Wang, X. (2007). Seismic damage model of concrete- filled rectangular tubular column (press in Chinese). Journal of Agricultural University of Hebei, 30 (3), 109-112.
[19] Han, L., Yang, Y., Tao, Z. (2003). Concrete-filled thinwalled steel SHS and RHS beam-columns subjected to cyclic loading. Thin-Walled Structures, 41 (9), 801-833.

[20] Li, X., Lü, X., Guo, S. (2005). Seismic behavior of CFRT columns under cyclic loading I: Experimental study (press in Chinese). Earthquake Engineering and Engineering Dynamics, 25 (5), 95-103.

[21] Yin, Y., Zhang, F., Ma, Y. (2012). Experimental research on seismic behavior of concrete-filled rectangular steel tubular columns (press in Chinese). Building Science Research of Sichuan, 38 (06), 190-192.

[22] Lu, X., Lu, W. (2000). Seismic behavior of concretefilled rectangular steel tubular columns under cyclic loading (press in Chinese). Journal of Building Structures, 21 (2), 2-11.

[23] Tao, Z., Han, L. (2001). Test of hysteresis behaviour of concrete filled steel tubular beam-columns with square sections (press in Chinese). Earthquake Engineering and Engineering Dynamics, 21 (1), 74-78.

[24] Yao, G., Han, L. (2004). Cyclic behavior of steel tube confined concrete beam-columns (press in Chinese). Earthquake Engineering and Engineering Dynamics, 24 (6), 89-96.

[25] Zhou, X., Liu, J., Zhang, S. (2010). Seismic behavior of square tubed steel reinforced concrete short columns (press in Chinese). Journal of Building Structures, 31 (7), 49-55.

[26] Zhang, S., Liu, J. (2007). Seismic behavior and strength of square tube confined reinforced-concrete (STRC) columns. Journal of Constructional Steel Research, 63 (9), 1194-1207.

[27] Ma, K., Liang, X., Li, B. (2010). Aseismic behavior of high strength concrete-filled rectangular steel tubular columns with high axial load ratio (press in Chinese). Engineering Mechanics, 27 (3), 155-162.

[28] Nie, R., Xu, P., Yan, Y. (2012). Experimental research and finite element analysis on seismic behavior of concrete-filled square steel tubular columns (press in Chinese). Journal of Tongji University, 40 (11), 15961602.

[29] Varma, A.H., Ricles, J.M., Sause, R., Lu, L. (2004). Seismic behavior and design of high-strength square concrete-filled steel tube beam columns. Journal of Structural Engineering-ASCE, 130 (2), 169-179.

[30] Wang, L., Wang, T., Chen, Q. (2003). Experimental study on seismic performance of concrete-filled rectangular tubular frame under low-reversed cyclic loading (press in Chinese). Earthquake Engineering and Engineering Dynamics, 23 (3), 113-117.

[31] Li, B., Ren, L. (2009). Experimental research on mechanical behavior of concrete filled RHS frames (press in Chinese). Engineering Mechanics, 26 (2), 103107,114 .

[32] Nie, J., Huang, Y., Yi, W., Fan, J. (2012). Seismic behavior of CFRSTC composite frames considering slab effects. Journal of Constructional Steel Research, 68 (1), 165-175. 
[33] Li, B., Li, X., Gao, C. (2012). Experimental research on seismic behavior of concrete-filled rectangular steel tubular planar frames (press in Chinese). Journal of Inner Mongolia University of Science and Technology, 31 (1), 85-89.

[34] Wang, X., Hao, J., Zhou, G., Zhang, Y., Ma, Y. (2010). Experimental research on seism ic behavior of two story two-bay concrete filled square steel tube columns frame (press in Chinese). Earthquake Engineering and Engineering Dynamics, 30 (3), 70-76.

[35] Liu, W., Ge, W., Lu, W. (2004). Experimental study on seismic behaviors of energy-dissipated braced frame structure with concrete-filled rectangular steel tubular columns and steel beams (press in Chinese). Earthquake Engineering and Engineering Dynamics, 24 (4), 106-109,114.

[36] Han, L., Wang, W., Zhao, X. (2008). Behaviour of steel beam to concrete-filled SHS column frames: Finite element model and verifications. Engineering Structures, 30 (6), 1647-1658.

[37] Li, B., Li, X. (2007). Finite element analysis of influence of axial load level on mechanical behavior of concrete-filled rectangular tubular frame (press in Chinese). Journal of Inner Mongolia University of Science and Technology, 26 (3), 257-260.

[38] Guo, R., Wang, T., Zhao, S.W., Wang, X. (2007). Seismic performance of reinforced damaged concretefilled rectangular tubular frame (press in Chinese). Journal of Tianjin University, 40 (1), 14-18.

[39] Padgett, J.E., Nielson, B.G., Desroches, R. (2008). Selection of optimal intensity measures in probabilistic seismic demand models of highway bridge portfolios. Earthquake Engineering \& Structural Dynamics, 37 (5), 711-725.
[40] Guan, M., Du, H., Cui, J., Zeng, Q., Jiang, H. (2015). Optimal ground motion intensity measure for longperiod structures. Measurement Science and Technology, 26 (10), 1-12.

[41] Montgomery, D.C., Runger, G.C., Hubele, N.F. (2011), Engineering Statistics. Wiley.

[42] OriginLab Corporation. OriginPro 8, version 8.0724 [computer software].

[43] Perea, T., Leon, R.T., Hajjar, J.F. (2014). Full-scale tests of slender concrete-filled tubes: Interaction behavior. Journal of Structural Engineering, 140 (9), 1-12.

[44] Patel, V.I., Liang, Q.Q., Hadi, M.N.S. (2017). Nonlinearanalysis of biaxially loaded rectangular concrete-filled stainless steel tubular slender beamcolumns. Engineering Structures, 140, 120-133.

[45] Liang, Q.Q., Patel, V.I., Hadi, M.N.S. (2012). Biaxiallyloaded high-strength concrete-filled steel tubular slender beam-columns, Part I: Multiscale simulation. Journal of Constructional Steel Research, 75, 64-71.

[46] Patel, V.I., Liang, Q.Q., Hadi, M.N.S. (2014). Numerical analysis of high-strength concrete-filled steel tubular slender beam-columns under cyclic loading. Journal of Constructional Steel Research, 92, 183-194.

Received February 25, 2019

Accepted July 30, 2019 